American Journal of Pharmaceutical Education 2019; 83 (7) Article 7178.

\title{
BRIEF
}

\section{Impact of a Pharmacy Student Organization on the Admissions Experience and Student Professional Development}

\author{
Shaina Kwiatkowski, PharmD, Kristin C. Klein, PharmD, Nancy A. Mason, PharmD \\ University of Michigan College of Pharmacy, Ann Arbor, Michigan \\ Submitted May 22, 2018; accepted January 31, 2019; published September 2019.
}

Objective. To evaluate the impact of a program which integrated student pharmacists into the admissions process on pharmacy school candidates' perceptions of the program and on participants' professional development.

Methods. An anonymous survey regarding the pharmacy school admission process was sent to candidates following their visit to campus and interviews from fall 2014 through spring 2017. A second survey of all student pharmacists enrolled in January 2018 was conducted to assess the impact of a student-led organization, Pharmacy Student Ambassadors (PSA), on their professional development. Results. The response rate for the survey completed by candidates was $66 \%(335 / 504)$ and the response rate for the survey completed by enrolled student pharmacists was 50\% (166/330). Almost all of the candidates were satisfied with the admissions process $(96 \%, 322 / 335)$. They cited the welcoming and friendly environment and opportunity to interact with student pharmacists as the best aspects of the admissions process. In the survey of enrolled students, the majority of PSA volunteers agreed or strongly agreed with statements regarding their organization's influence on professional development (76\%), enhancing communication skills (77\%), self-reflection (78\%), and feeling respected and valued (73\%). Furthermore, the majority of student pharmacists agreed or strongly agreed that participation in the PSA positively impacted their own admissions process (87\%), made interviewees more at ease and comfortable $(88 \%)$, increased their knowledge and understanding of the culture in the program ( $82 \%$ and $75 \%$ respectively), and influenced their personal decisions to attend the University of Michigan College of Pharmacy (63\%).

Conclusion. Student pharmacist involvement in the admissions process was correlated with pharmacy school candidate satisfaction and contributed to enrolled students' positive perceptions regarding their professional development.

Keywords: student ambassadors, admission, interview, professional development

\section{INTRODUCTION}

The Accreditation Council for Pharmacy Education (ACPE) "Standards 2016" requires pharmacy schools to conduct candidate interviews as part of the admissions process. ${ }^{1}$ The faculty at the University of Michigan College of Pharmacy (UM-COP) values the participation of student pharmacists in the recruitment and interview process of candidates because we believe students' involvement enhances the experience for candidates. Similarly, we have heard from enrolled students that they appreciate the experience of interacting with candidates and "sitting on the other side of the table" for interviews. However, we had not conducted a formal evaluation of the effects of current student participation on prospective or current

Corresponding Author: Nancy A. Mason, University of Michigan College of Pharmacy, 428 Church St., Ann Arbor, MI. Tel: (734) 763-4981. Email: nmason@umich.edu students. This paper describes UM-COP's Pharmacy Student Ambassadors (PSA) organization ${ }^{2}$ and the college's quality assurance evaluation, reporting on both prospective candidates' and current student members' perceptions of the PSA.

The UM-COP conducts weekly individual interviews with candidates over several weeks during the academic year (October to March) to facilitate more personal connections between the candidate and the school during the process. During their visit, candidates have two back-to-back interview sessions with two interviewers present in each session. To help fill the need for interviewers and give current students leadership opportunities, the Pharmacy Student Ambassadors (PSA) was formed in 2010. Over time, the PSA has evolved to meet other needs beyond participating in interviews and the organization is now an essential component of several aspects of the recruitment and admissions process. 


\section{American Journal of Pharmaceutical Education 2019; 83 (7) Article 7178.}

The mission of the PSA is to enrich the admissions experience by creating a welcoming environment and offering a variety of perspectives to candidates. Since its inception, the PSA has grown into the largest student organization within the college and includes nearly 200 members each year. With an average class size of 85 students per year, the PSA encompasses over two-thirds of first through third-year student pharmacists. The organization is comprised of 40 elected student leaders who head several committees that provide a broad range of events and activities to support the operations of the recruitment and admissions office (Figure 1). As mentioned earlier, a major role of the PSA is enlisting and coordinating student volunteers to participate in formal admission interview days in conjunction with the director of admissions, who also serves as the staff advisor to PSA. On average, 10 pharmacy school candidates are interviewed during each of the 18 to 20 weekly interview days, and 27 student pharmacist volunteers are needed for each day. For prospective candidates, the admission interview day consists of two 35-minute interviews, each with a faculty member and student pharmacist pair, lunch at a local venue with a student pharmacist panel, attendance of a first-year pharmacy class, and a hospital tour led by student pharmacist interns. Prior to the interview day, each candidate is paired with a student pharmacist who emails them at least one week before the interview with information about interview preparation, housing, and the city, and to answer any questions. Emails to candidates during the admissions process use a standardized template as the basis for messages. If a candidate is accepted into the program, the same student pharmacist sends a congratulatory email to the candidate with links to resources on how to connect with other accepted candidates and current students. The PSA recruits volunteers prior to the fall and winter semesters and creates a weekly schedule of which students will be helping with which activities, and sends the schedule to the director of admissions.

At the beginning of each semester, the PSA volunteers are trained by the director of admissions on how to conduct interviews. Interviewers are given a list of possible interview questions to ask, including a standardized situational question. After interviewing each candidate, the faculty interviewer and student interviewer debrief on the interview and independently use a standardized rubric to score the candidate on core measures, including communication, ethics, and leadership skills.

Along with having a major presence during admission interview days, the PSA is involved with ongoing recruitment efforts for the college (Figure 2). For example, the PSA has close ties with the Pre-Pharmacy Student Organization at the university, through which student pharmacists assist with established mentorship programs, mock interview opportunities, and pharmacy career exploration events. Additionally, select student pharmacists serve as liaisons between the college and undergraduate pre-pharmacy organizations across the country. Finally, the PSA uses social media platforms such as Facebook, Instagram, and blogs to share stories and photos about life as a student pharmacist. Through each of these efforts, the PSA informs pharmacy school candidates about the program and culture within the College.

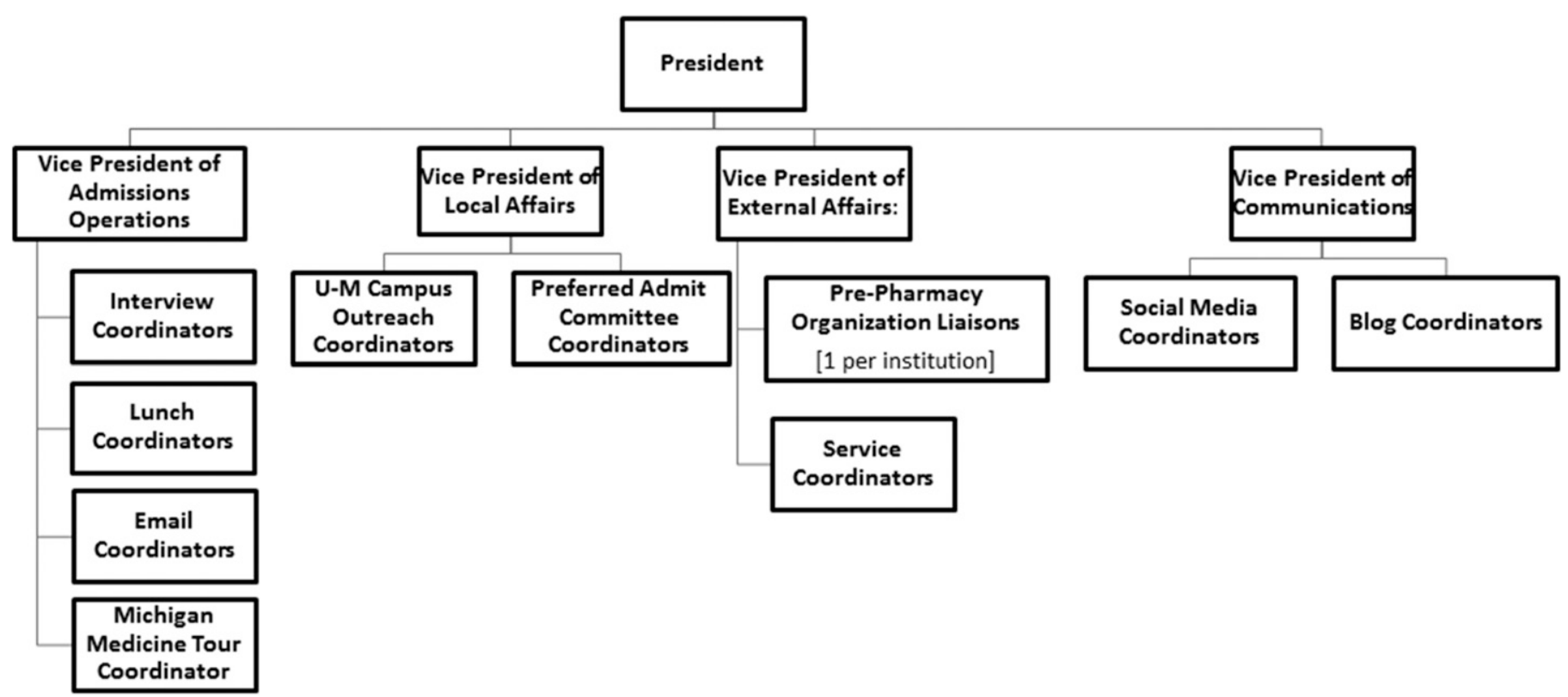

Figure 1. Pharmacy Student Ambassadors Leadership Structure 


\section{American Journal of Pharmaceutical Education 2019; 83 (7) Article 7178.}

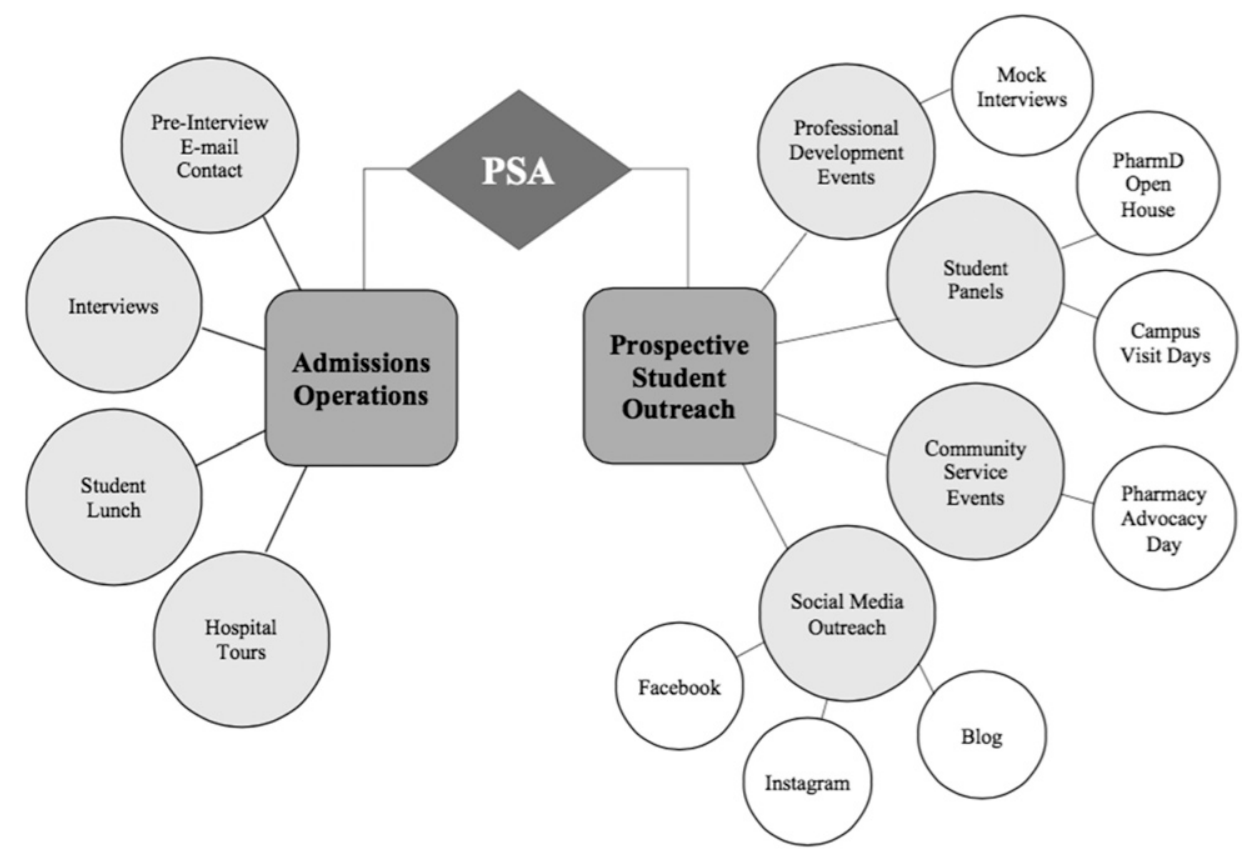

Figure 2. Pharmacy Student Ambassadors Organizational Structure

A simple Google search for pharmacy student ambassadors will reveal many schools using student pharmacists in their recruitment and admissions processes. Additionally, a formal literature search found that other health science schools have described similar student ambassador programs. ${ }^{3,4}$ However, there is limited literature describing the roles and impact of integrating student pharmacists into such processes. The objective of this study was to assess pharmacy school candidates' and enrolled students' perceptions regarding student pharmacist involvement in the admissions process. We hypothesized that pharmacy school candidates perceived student pharmacists' involvement as a positive aspect of the admissions experience. We also hypothesized that student pharmacists who had participated in the PSA program experienced professional development and improved communication skills, and felt respected and valued for their contributions. These hypotheses were based on anecdotal evidence and student reflections regarding professionalism that had previously been gathered.

\section{METHODS}

The college's satisfaction survey instrument that was sent to candidates after their interview had been developed internally as a quality assurance tool and was specific to UM's pharmacy program. This anonymous survey solicited information from candidates regarding their satisfaction with the information provided prior to their interview (ie, interview schedule, travel and parking information, student email greeting), several components of the interview day (informational session, lunch with students, classroom session, hospital tour), and their overall satisfaction with the interview process. The candidates were asked to rate each item on a four-point Likert scale (very satisfied, somewhat satisfied, somewhat dissatisfied, very dissatisfied). Candidates were also asked to provide open-ended comments about their favorite part of the day and to identify areas for improvement. This survey was distributed by the director of admissions through email to candidates within one week after their interview during three admission cycles, including 2014-2015, 2015-2016, and 2016-2017. Students were given one week to complete the survey on Qualtrics (Provo, UT), and the survey was closed before the candidates received an admission decision. Survey results were analyzed using descriptive statistics and open-ended comments were evaluated qualitatively.

The survey instrument sent to current students was developed by the authors and designed to assess whether students participating in the PSA experienced professional development through participation in the organization and to evaluate the impact of the PSA on their own admissions experience. A request to complete the anonymous Qualtrics survey was sent by email to all student pharmacists enrolled at UM-COP in January 2018. Demographic information was collected, including year in pharmacy school and number of years of participation in PSA. Those who indicated they had participated in PSA were then directed electronically to a section of the survey for PSA volunteers only where additional demographic 


\section{American Journal of Pharmaceutical Education 2019; 83 (7) Article 7178.}

Table 1. Most Liked Aspects of the Interview Process Identified by Prospective Pharmacy School Candidates as Part of a Study to Determine the Impact of Student Pharmacists Participating in the Recruitment and Interview Process $(\mathrm{N}=323)$

\begin{tabular}{|c|c|c|}
\hline Category & $\mathbf{N}$ & Sample Comments \\
\hline $\begin{array}{l}\text { Welcoming/friendly/ } \\
\text { relaxed }\end{array}$ & 106 & $\begin{array}{l}\text { Reduced stress associated with the interview process, positive atmosphere, approachable, } \\
\text { enjoyable, made me feel comfortable, professional atmosphere, sense of community, } \\
\text { warmth; felt inviting }\end{array}$ \\
\hline Students & 98 & $\begin{array}{l}\text { Relaxing to have current student in the interview to answer questions about the life as a } \\
\text { student pharmacist; very impressed by all of the contact I received from the school prior } \\
\text { to the interview, including interview information as well as being welcomed by a } \\
\text { student; heard several opinions as opposed to just one; friendly }\end{array}$ \\
\hline $\begin{array}{l}\text { Introductory session } \\
\text { with the Director } \\
\text { of Admissions }\end{array}$ & 71 & $\begin{array}{l}\text { Empathetic; relaxing environment; funny; personable; made me feel less anxious and } \\
\text { nervous; made the process smooth and enjoyable; cares for all students and prospective } \\
\text { students; inviting; made an effort to get to know each candidate; inspirational; gave me } \\
\text { a great impression of what the school will actually be like; great interview tips }\end{array}$ \\
\hline Classroom & 63 & $\begin{array}{l}\text { Enjoyed sitting in on the Pharmaceutical Sciences class; students were eager to talk to the } \\
\text { candidates; made me feel welcome; I would love to learn in that type of environment } \\
\text { with students like that if accepted; enjoyed the opportunity to participate in an exercise } \\
\text { with current students }\end{array}$ \\
\hline Faculty/staff & 47 & $\begin{array}{l}\text { Enthusiastic and caring about the students' education; very knowledgeable; friendly } \\
\text { nature of staff and faculty; genuine; inviting }\end{array}$ \\
\hline Lunch & 46 & $\begin{array}{l}\text { Comfortable setting to ask questions; informative; relaxed; informal; got an insider's } \\
\text { perspective; casual setting; great opportunity to explore the community; best way to } \\
\text { steady nerves after the interview block }\end{array}$ \\
\hline Tour & 41 & $\begin{array}{l}\text { Liked the opportunity to see what opportunities I will have as a student; informative to get } \\
\text { a sense of how clinical pharmacy works; inspiring; impressed by the exposure that } \\
\text { students have to different residency options and non-traditional pharmacy roles directly } \\
\text { at the university }\end{array}$ \\
\hline Interview itself & 39 & $\begin{array}{l}\text { Liked duel interviewers with both faculty and student allows for multiple perceptions and } \\
\text { opinions; conversational; relaxed; non-judgmental; student pharmacists during the } \\
\text { interview made the process less stressful }\end{array}$ \\
\hline $\begin{array}{l}\text { Interview day } \\
\text { structure }\end{array}$ & 20 & $\begin{array}{l}\text { Liked having the interviews in the morning, followed by lunch, classroom visit, and tour; } \\
\text { smooth, well organized; interactive; relaxing day after interviews; informational; we } \\
\text { were given the chance to experience every aspect of what life in pharmacy school will } \\
\text { be like, whether it was the classroom sessions or rotations in the hospital }\end{array}$ \\
\hline
\end{tabular}

information was collected, including leadership positions held in PSA. Students were asked to report the number of PSA activities they had participated in (eg, email contact, interviews, lunches, hospital tours) on a scale of zero, one to three, four to six, seven to nine, and greater than or equal to 10. Survey participants were asked to respond to statements regarding professional development using a five-point Likert scale on which $1=$ strongly disagree and $5=$ strongly agree. Also, an open-ended comment section asked PSA volunteers how participation in PSA impacted their professional development.

The last section of the survey instrument was open to all student pharmacists, regardless of PSA participation. Responses to items regarding the impact of the PSA in their own admissions experiences were answered using a fivepoint Likert scale, and an open-ended comment section was available for students who wanted to provide more de- tailed answers. Students were given 10 days to complete the survey on Qualtrics. A reminder announcement was made in person to first- and third-year student pharmacists, and a reminder email was sent on day nine to all student pharmacists.

Responses on both surveys were quantitatively analyzed using descriptive statistics, and open-ended questions were qualitatively analyzed by sorting comments into themed categories and counting the number of times students mentioned that theme. Linear regressions and chi square tests were used to assess correlations between professional development and participation in PSA leadership or involvement (number of activities they participated in). Statistical significance was defined as a $p$ value $<.05$. All statistical analyses were done in $\mathrm{R}$, version 3.4.0 (R Foundation for Statistical Computing, Vienna, Austria). This project was submitted to the UM institutional review board and was deemed exempt from review. 


\section{American Journal of Pharmaceutical Education 2019; 83 (7) Article 7178.}

Table 2. Least Liked Aspect of the Interview Process Identified by Pharmacy School Candidates Surveyed as Part of a Study to Determine the Impact of Student Pharmacists Participating in the Recruitment and Interview Process $(\mathrm{N}=267)$

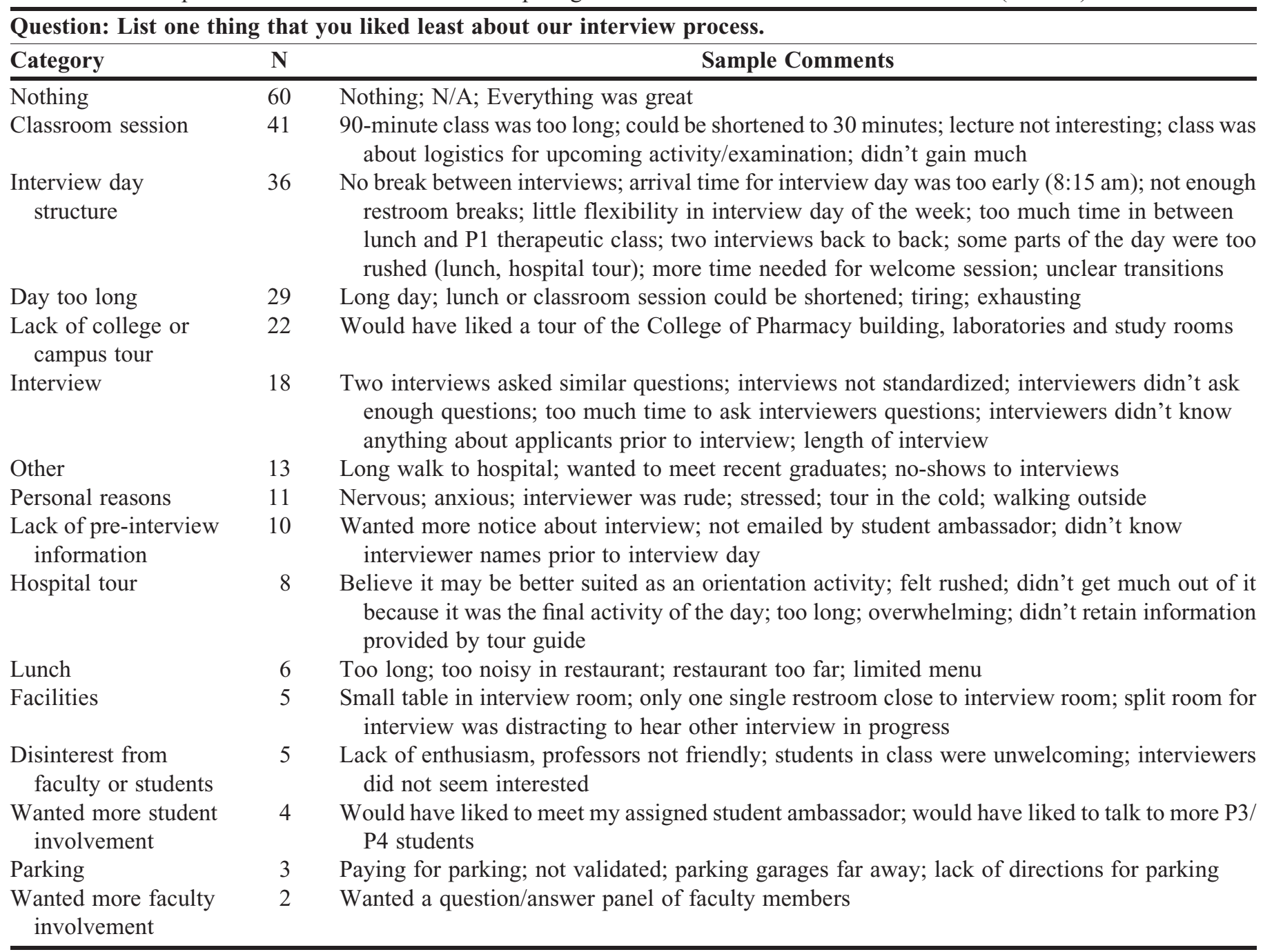

Abbreviations: P1 = first professional year, P3 = third professional year, P4=fourth professional year

\section{RESULTS}

The overall response rate for the pharmacy student candidate survey was $66 \%$ (335 of 504). Nearly all survey participants expressed satisfaction with the admission experience (322 of 335, 96\%). Similarly, nearly all survey participants agreed that the email sent by the PSA volunteer prior to interview day was welcoming $(97 \%)$, friendly (97\%), and informative (96\%). In response to what they liked most about the interview day, most candidates used terms like welcoming, friendly, and relaxed environment (Table 1). Many candidates attributed these feelings about the interview day to their interactions with current students, the director of admissions, and faculty members. The word "student" appeared in 98 out of 323 comments, and was one of the most common themes in the comment section. When asked about the least liked aspect of the admission experience, the most common response was "nothing" or "not applicable" (Table 2). When a specific response was provided, the most commonly disliked element was the classroom session. Although prospective candidates appreciated seeing a pharmacy class in session, candidates noted that a full class was too long or the subject was not interesting compared to other components of the interview day.

The overall response rate for the current student survey was $50 \%$ (166 of 330). There was representation from students in each year of the program, with proportionally more participants from the first-year class (Table 3). One hundred thirty-one of the students who responded had participated in the PSA, and 49 had held leadership positions. Of the participants, the average number of years served in the PSA was 2.1 years. Students reported participating in one to three PSA activities on average with the exception of hospital tours, which were new to the program in 2017 and mainly led by hospital pharmacy interns. 


\section{American Journal of Pharmaceutical Education 2019; 83 (7) Article 7178.}

Table 3. Demographics of Student Pharmacists Surveyed as Part of a Study to Determine the Impact of Student Pharmacists Participating in the Recruitment and Interview Process

\begin{tabular}{lr}
\hline & N (\%) \\
\hline Year in pharmacy school $(\mathrm{N}=166)$ & $54(33)$ \\
$\quad$ First & $32(19)$ \\
Second & $46(28)$ \\
Third & $34(20)$ \\
Fourth & $131(79)$ \\
Number of PSA participants $(\mathrm{N}=166)$ & \\
Number of years participated in PSA $(\mathrm{N}=166)$ & $35(21)$ \\
Zero & $53(32)$ \\
One & $30(18)$ \\
Two & $37(22)$ \\
Three & $11(7)$ \\
Four & $49(37)$ \\
Leaders in PSA $(\mathrm{N}=131)$ & \\
\hline
\end{tabular}

Abbreviations: PSA $=$ Pharmacy Student Ambassadors

The majority of PSA participants agreed with statements regarding professional development $(76 \%)$, enhancing communication skills (77\%), self-reflection $(78 \%)$, and feeling respected and valued $(73 \%)$. The results were evaluated further by comparing leaders and non-leaders in PSA with regard to these outcomes (Table 4). In all but one category (feeling respected and valued), a higher proportion of leaders vs non-leaders agreed that they had benefited from participation in PSA. A significantly higher percentage of PSA leaders agreed with the statement about professional development than nonleaders ( $88 \%$ vs $68 \%$, respectively; $p<.001$ ) (Table 4 ). When analyzing the correlation between number of activities participated in and professional development outcomes, all four measures had a significant positive correlation to number of activities (Table 5). When asked how participating in the PSA had impacted their professional development, some common themes were improving their interview skills, communication skills, and mentorship capabilities (Table 6).

The second part of the survey instrument included all student pharmacists, regardless of participation in PSA $(\mathrm{N}=166)$. The majority (63\% to $88 \%)$ of survey participants agreed with statements regarding the positive impact of student pharmacist involvement in their own admission process (Table 7). Finally, survey participants reported similar comments as those reported in the survey of candidates regarding their admission day experience. Common themes included appreciation for being able to hear the students' perspectives, having a comfortable environment in which to ask candid questions, and being given the opportunity to experience the culture at the UM-COP.

\section{DISCUSSION}

The results of this study strongly support involving student pharmacists in admissions and recruitment efforts. We believe that candidates' high satisfaction rates with the overall admissions process were influenced by the substantial involvement of the PSA. Introducing student pharmacists to candidates by email before the interview day gives

Table 4. Impact of the Pharmacy Student Ambassadors Organization on Professional Development Outcomes for Leaders vs NonLeaders

\begin{tabular}{|c|c|c|c|c|c|c|c|c|c|}
\hline \multirow[b]{2}{*}{ Question } & \multicolumn{4}{|c|}{ Leaders Only, $N=49$} & \multicolumn{4}{|c|}{ Non-Leaders Only, $\mathrm{N}=82$} & \multirow[b]{2}{*}{$\begin{array}{c}p \\
\text { value }\end{array}$} \\
\hline & $\begin{array}{c}\text { Strongly } \\
\text { Agree/ } \\
\text { Agree, } \\
\text { N (\%) }\end{array}$ & $\begin{array}{l}\text { Neutral, } \\
\text { N (\%) }\end{array}$ & $\begin{array}{c}\text { Strongly } \\
\text { Disagree/ } \\
\text { Disagree, } \\
\text { N (\%) }\end{array}$ & $\begin{array}{l}\text { Mean } \\
\text { (SD) }\end{array}$ & $\begin{array}{c}\text { Strongly } \\
\text { Agree/ } \\
\text { Agree, } \\
\text { N (\%) }\end{array}$ & $\begin{array}{l}\text { Neutral, } \\
\text { N (\%) }\end{array}$ & $\begin{array}{c}\text { Strongly } \\
\text { Disagree/ } \\
\text { Disagree, } \\
\text { N (\%) }\end{array}$ & $\begin{array}{l}\text { Mean } \\
\text { (SD) }\end{array}$ & \\
\hline \multicolumn{10}{|l|}{ My participation in PSA has: } \\
\hline $\begin{array}{l}\text { Developed myself } \\
\text { professionally }\end{array}$ & $43(88)$ & $5(10)$ & $1(2)$ & $4.1(0.76)$ & $56(68)$ & $19(23)$ & $7(9)$ & $3.7(0.84)$ & .00 \\
\hline $\begin{array}{l}\text { Enhanced my } \\
\text { communication skills }\end{array}$ & $40(82)$ & $8(16)$ & $1(2)$ & $4.1(0.81)$ & $61(74)$ & $16(20)$ & $5(6)$ & $3.8(0.82)$ & .17 \\
\hline $\begin{array}{l}\text { Helped me to self-reflect } \\
\text { on the qualities } \\
\text { necessary to succeed as } \\
\text { a student and } \\
\text { pharmacist }\end{array}$ & $41(84)$ & $7(14)$ & $1(2)$ & $4.2(0.76)$ & $61(74)$ & $14(17)$ & $7(9)$ & $3.9(1.0)$ & .08 \\
\hline $\begin{array}{l}\text { Made me feel respected } \\
\text { and valued }\end{array}$ & $35(71)$ & $12(24)$ & $2(4)$ & $4.0(0.95)$ & $60(73)$ & $18(22)$ & $4(5)$ & $3.9(0.87)$ & .75 \\
\hline
\end{tabular}

Mean and percentages are based on a 5-point Likert scale: strongly disagree $=1$, disagree $=2$, neutral $=3$, agree $=4$, strongly agree $=5$ Abbreviations: PSA $=$ Pharmacy Student Ambassadors 


\section{American Journal of Pharmaceutical Education 2019; 83 (7) Article 7178.}

Table 5. Number of Activities Correlated to Professional Development Outcomes for Pharmacy Student Ambassadors

\begin{tabular}{|c|c|c|}
\hline \multirow[b]{2}{*}{ Question } & \multicolumn{2}{|c|}{ Number of Activities } \\
\hline & $95 \% \mathrm{CI}$ & $p$ value \\
\hline \multicolumn{3}{|l|}{ My participation in PSA has: } \\
\hline Developed myself professionally & $0.05-0.18$ & .00 \\
\hline Enhanced my communication skills & $0.05-0.18$ & $<.01$ \\
\hline $\begin{array}{l}\text { Helped me to self-reflect on the qualities necessary to } \\
\text { succeed as a student and pharmacist }\end{array}$ & $0.06-0.2$ & $<.01$ \\
\hline Made me feel respected and valued & $0.03-0.17$ & .01 \\
\hline
\end{tabular}

Abbreviations: $\mathrm{CI}=$ Confidence Interval, $\mathrm{SD}=$ standard deviation, $\mathrm{PSA}=$ Pharmacy Student Ambassadors

candidates a personal contact to go to with questions. Ideally, email contacts are paired with candidates based on undergraduate institution so that the ambassador is more relatable and can answer questions specific to their current institution. During the interview day, the candidates appreciate having both faculty members and students conduct the interview. Each interviewer provides a different perspective on the qualities needed to excel in pharmacy school and in the profession, while maintaining a relaxed environment. All interviewers, whether faculty mem- bers or students, provide feedback on the candidates using a standardized rubric and their feedback is considered equally by the admissions committee. The PSA students who take candidates to lunch, accompany them to class, or conduct tours following the interview have no influence on the admission decision regarding the candidate. This gives the candidate opportunities to ask candid questions in a low-stakes environment. Because candidates encounter multiple students in each activity, they can hear a variety of insider perspectives on life as a student.

Table 6. Impact of Involvement in the Pharmacy Student Ambassadors Organization on Student Pharmacists' Professional Development (Sample Comments) $(\mathrm{N}=45)$

\begin{tabular}{|c|c|}
\hline $\mathbf{N}$ & Sample Comments \\
\hline 23 & $\begin{array}{l}\text { Great way for students to attain a better understanding of what interviewers look for in candidates as } \\
\text { they move on in their careers. } \\
\text { Interviewing candidates has really helped improve my own interviewing skills and confidence. } \\
\text { It makes me more comfortable in interviews. They are less intimidating after being on the other side of } \\
\text { the table. } \\
\text { Participating as an interviewer has helped me see interviews from a different perspective and realize } \\
\text { how important it is for the candidate to assess whether the school/job is a good fit, not just whether } \\
\text { the school/job wants the candidate. }\end{array}$ \\
\hline 14 & $\begin{array}{l}\text { I was able to interact with faculty and potential student pharmacists in a respectful and professional } \\
\text { environment. } \\
\text { I have learned how to handle and communicate through unexpected situations. }\end{array}$ \\
\hline 8 & $\begin{array}{l}\text { I more valued participating in PSA to give back to the community and help pre-health students decide } \\
\text { if pharmacy is right for them. } \\
\text { PSA has given me the opportunity to stay connected with the reasons I chose pharmacy because I need } \\
\text { to talk about that with prospective students and in presentations...I have grown professionally } \\
\text { through PSA and hope to continue to advocate for pharmacy and be a resource/role model for } \\
\text { prospective students. }\end{array}$ \\
\hline 7 & $\begin{array}{l}\text { It was rewarding to be able to advocate for the College of Pharmacy. } \\
\text { Participating in PSA has given me a taste of what giving back to the profession means. }\end{array}$ \\
\hline 7 & $\begin{array}{l}\text { It has helped me to learn how to manage my time well and stay organized. } \\
\text { Participating in PSA helped me to grow in my image as a professional. I had a professional role that } \\
\text { helped me to understand and value my role at the College more. }\end{array}$ \\
\hline 5 & $\begin{array}{l}\text { It has helped me learn about aspects of recruiting and also how to run large operations, such as } \\
\text { interviews, smoothly. } \\
\text { It taught me how to better communicate with others, how to delegate tasks, and how to work together } \\
\text { towards a common goal. }\end{array}$ \\
\hline
\end{tabular}




\section{American Journal of Pharmaceutical Education 2019; 83 (7) Article 7178.}

Table 7. Impact of the Pharmacy Student Ambassadors Organization on Students Pharmacists' Admissions Experience and Decision to Attend $(\mathrm{N}=166)$

\begin{tabular}{lccrr}
\hline Question & $\begin{array}{c}\text { Strongly Agree/Agree, } \\
\text { N (\%) }\end{array}$ & $\begin{array}{c}\text { Neutral, } \\
\text { N (\%) }\end{array}$ & $\begin{array}{c}\text { Strongly Disagree/ } \\
\text { Disagree, N (\%) }\end{array}$ & $\begin{array}{c}\text { Mean } \\
\text { (SD) }\end{array}$ \\
\hline $\begin{array}{l}\text { Pharmacy student participation in the admissions } \\
\text { process at University of Michigan College of }\end{array}$ & & & & \\
$\quad$ Pharmacy (U-M COP): & $144(87)$ & $16(10)$ & $6(4)$ & $4.3(0.86)$ \\
$\quad \begin{array}{ll}\text { Positively impacted the admissions process } \\
\text { Made me feel more at ease and comfortable }\end{array}$ & $146(88)$ & $14(8)$ & $6(4)$ & $4.4(0.81)$ \\
Increased my knowledge of U-M COP & $136(82)$ & $20(12)$ & $10(6)$ & $4.1(0.92)$ \\
Enhanced my understanding of the culture at the & $125(75)$ & $28(17)$ & $13(8)$ & $4.0(0.95)$ \\
$\quad$ U-M COP & $104(63)$ & $38(23)$ & $24(14)$ & $3.7(1.15)$ \\
Influenced my decision to attend the U-M COP & & & & \\
\hline
\end{tabular}

Mean and percentages are based on a 5-point Likert scale: strongly disagree $=1$, disagree $=2$, neutral $=3$, agree $=4$, strongly agree $=5$

Abbreviations: $\mathrm{SD}=$ standard deviation, $\mathrm{U}-\mathrm{M} \mathrm{COP}=$ University of Michigan College of Pharmacy, PSA $=$ Pharmacy Student Ambassadors

As pharmacy students reflected on their experiences during the admissions process, many expressed gratitude towards the student ambassadors who had made it a positive experience. The PSA members noted that they became an ambassador to give back to the college and the profession, as well as to provide mentorship to prospective candidates. Members of the PSA benefit in terms of professional development, improving their communication and interview skills, and being given leadership opportunities, which contributes to the overall co-curricular program and helps meet ACPE standards for personal and professional development (Standard 4, Professionalism and Leadership). ${ }^{1}$ Although leaders in the PSA reported experiencing more professional growth than did non-leaders, even the non-leaders strongly agreed with each statement, indicating positive benefits from their participation in the PSA. Furthermore, when answering questions from candidates, members of the PSA were challenged to reflect on why they chose pharmacy as a career and what characteristics are needed to succeed as a student pharmacist and pharmacist. The PSA volunteers also enjoyed the opportunity to network with faculty members at the UM-COP when interviewing candidates.

When reflecting on their own admission experiences, current students reported positive feelings towards the PSA similar to those reported by prospective pharmacy student candidates. There was a lower than expected percentage of students agreeing with the statement that the PSA influenced their decision to attend the UM-COP. It was unclear why the PSA had a limited impact on students' decision to attend our program; however, the survey instrument did not assess the candidate's preexisting view of the program. Thus, candidates may have already had a positive view of the program, or other aspects not assessed by the instrument may have influenced their decision to attend UM-COP.
In addition to benefiting candidates and student pharmacists, the PSA provides an important benefit to the UM-COP admissions department. Because PSA is a student-run organization, leadership of PSA recruits ambassadors and schedules them for the admissions process in conjunction with the director of admissions. This saves the director of admissions a significant amount of time. Also, involving students as interviewers lessens the burden on faculty members and expands the influence of students.

This study has several limitations. The pharmacy school candidates may have felt pressure to provide positive feedback about their experience in order to improve the odds of admission, even though the survey was anonymous and candidates' responses did not factor into their admission decision. Also, because it was anonymous, there was no way to compare the feedback of those candidates who were admitted and matriculated to those who were not admitted or who were accepted but chose not to come to our college. The student pharmacist survey was subject to selection bias as $79 \%$ of the survey participants were members of the PSA. This proportion was slightly higher than the percentage of current students who participate in PSA. Also, it reflects only those who were admitted and there was no comparator group. This study reflects just one pharmacy school's experience, thus the findings may not be applicable to other schools.

Areas for improvement were also gleaned from the results of this study. We would like to include more fourth-year student pharmacists in the admissions process, although their rotation schedules usually prohibit involvement in on-site interviews. However, they could offer a meaningful perspective to candidates through email contacts. Also, some candidates who were interviewed in the fall semester were not fond of the class visit because only a lecture-format course was available. 


\section{American Journal of Pharmaceutical Education 2019; 83 (7) Article 7178.}

Those who were interviewed during the winter term were much more intrigued with the class visit to the therapeutics course, which is taught using a team-based learning format. The PSA is considering adding a student-run team-based learning exercise in place of the class visit during fall term. Finally, with so many student participants in the interview process, there is a need for more quality assurance measures to improve the consistency of the interview experience for candidates.

The UM-COP is one of several institutions with ambassador programs. For example, a Google search revealed that pharmacy programs at the University of Missouri-Kansas City, ${ }^{5}$ University of Wisconsin-Madison, ${ }^{6}$ and University of Oklahoma had ambassador programs. ${ }^{7}$ The ambassador program at our institution shares comparable elements to other programs, such as recruitment events, tours, student panels, and involvement in the interview process. One major difference in our program is that any student pharmacist can become an ambassador by participating in at least one PSA activity per year. Other programs have specific requirements and an application process to become an ambassador as well as a limit to how many students can join. Our program operates under the philosophy that any current student can join and benefit from participating. However, because there are no membership requirements for PSA members, there is a range in the degree of participation and the extent to which participants gain professional development. This was evident by the significant positive correlation between the number of activities and percentage of agreement with the professional development statements. Another difference is that our PSA organization is solely student-run, with the director of admissions serving as the staff advisor. This model gives student leaders of PSA independence to shape the organization, with minimal oversight. Other than receiving a pin of appreciation and free lunch on interview days, student volunteers are not paid or otherwise incentivized.

\section{CONCLUSION}

Student pharmacist involvement in the admissions and recruitment processes enhances the experience of prospective candidates by providing first-hand insight into pharmacy school culture and contributes to the professional growth of current student pharmacists. Our institution serves as an example of a comprehensive ambassador program that shows great benefit to both pharmacy school candidates and current students. Other schools may consider adding a similar program to enrich their admissions and recruitment efforts.

\section{REFERENCES}

1. American Council Pharmaceutical Education. Accreditation standards and key elements for the professional program in pharmacy leading to the Doctor of Pharmacy degree (Standards 2016). https:// www.acpe-accredit.org/pdf/Standards2016FINAL.pdf. Published February 2015. Accessed January 15, 2019.

2. Pharmacy Student Ambassadors, University of Michigan College of Pharmacy. https://pharmacy.umich.edu/psa. Accessed January 15, 2019.

3. Rhodes S, Sherwin C, Smith L. The role of student ambassadors in university recruitment. Nursing Standard. 2006;20(34):44-48.

4. James H. Development of a student ambassador program. UNLV

Theses, Dissertations, Professional Papers, and Capstones. 2008;430.

5. Student Ambassadors, School of Pharmacy, University of Missouri-Kansas City. https://pharmacy.umkc.edu/current-students/ student-ambassadors/. Accessed January 15, 2019.

6. Becoming an Ambassador, University of Wisconsin-Madison School of Pharmacy, Board of Regents of the University of Wisconsin System. https://pharmacy.wisc.edu/student-organizations/ ambassador-program/becoming-an-ambassador/. Accessed January 15,2019

7. OUCOP Student Ambassador Program: Service, Leadership, and Professionalism, The University of Oklahoma College of Pharmacy. https://pharmacy.ouhsc.edu/programs/doctor-of-pharmacy/ studentambassadors. Accessed January 15, 2019. 